\title{
Digit Ratio and Soccer
}

\author{
Muhammad Shahidul Islam ${ }^{1,2 *}$ and Brajanath Kundu ${ }^{3}$ \\ ${ }^{1}$ Office of Physical Education, Shahjalal University of Science and Technology, Bangladesh \\ ${ }^{2}$ Department of Physical Education and Sport Science, Visva Bharati University, India \\ ${ }^{3}$ Department of Physical Education and Sport Science, Visva Bharati University, India
}

*Corresponding author: Muhammad Shahidul Islam, Department of Physical Education and Sport Science, Visva-Bharati University, West Bengal, India

\begin{abstract}
The ratio between the lengths of index finger in relation to the length of ring finger of a palm is noticed to as second to fourth digit ratio. Digit ratio tented to shows the quantity of male hormone, to which an individual is exposed in the womb of the mother. Several investigations establish the negative relationship between lower digit ratio and various sports performance as the lower digit ratio settle the high prenatal testosterone hormone. The exposure of prenatal androgenisation masculinizes the human body that impacts the efficiency of sports. Soccer player perceives numerous situations and makes instantaneous decisions. Experienced players are reading the game and anticipating the next move of the opponent. Previous studies have demonstrated the link between cognitive ability and the digit ratio. Similarly, players have numerous cognitive skills to dictate soccer game such as spatial intelligence, awareness, and visual spatial ability. Here, we explore the possible causes of negative associations between lower second to fourth digit ratio and soccer performance. We also think soccer-specific skill performance is likely to be associated with lower digit ratio
\end{abstract}

Keywords: Digit ratio; Testosterone; Estrogen; Soccer

\section{Introduction}

The peripheral blood cannot be extracted in utero from fetuses [1]. The second to fourth digit ratio (2D:4D) was therefore suggested as a prenatal testosterone marker [2]. Manual second to fourth digit ratio (2D:4D) at the end of the first trimester of pregnancy is believed to be a biomarker of the balance between prenatal testosterone and prenatal estrogen hormone [2-4]. Thereafter, the digit ratio (2D:4D) probably remain unchanged throughout the life [2]. However, Manning (2002) indicated that the digit ratio (2D:4D) was set particularly between week 8 and 12 at the end of the first trimester. The male fetuses mainly produce large quantities of testosterone hormone, primarily from their testis and adrenal glands [5]. This influences brain and other organ systems development [2-6]. In general, the length of index (2D) and ring fingers (4D) in women is about the same (digit ratio=1.00), whereas in men the ring finger is generally slightly longer (digit ratio=0.98) [7]. The length difference between the two digits is higher for men than for women [8-9]. Testosterone influences the growth of the ring finger (4D), whereas estrogen exposure stimulates the growth of the index finger (2D) [7]. The ratio of the index finger to the ring finger (2D:4D) has been shown to be a sexually dimorphic trait [9-10]. Additionally, the ratio of digits
(2D:4D) measured by the length of index finger divided by the length of ring finger [7-11]. Therefore, researchers found an index of prenatal testosterone exposure relative to prenatal estrogen exposure [7-12]. The prenatal androgen is likely to be increase, if the digit ratio goes down [7]. Several studies portray the second to fourth digit ratio in which prenatal testosterone hormone was associated. The researches recommend that the lower ratio of digit is a noninvasive feasible indicator for sport success rate Manning and Taylor [13] ; Manning and Hill [14] ;Manning et al. [8]; Hone and McCullough [15] ; Longman et al. [16]; Sudhakar et al. [17]; Sudhakar et al. [18]; Bennett et al. [19]; Kim [20]. As because, adult lower digit ratio (2D:4D) promote the masculine feature [2]. The testosterone $(\mathrm{T})$ is a steroid hormone that develops and maintain masculine feature of human body [21]. The specific aim of this review study was to explore the relationship between digit ratio (2D:4D) and soccer performance.

\section{How does the digit ratio ( $2 \mathrm{~d}: 4 \mathrm{~d})$ fixed?}

The adult finger length ratio is becoming a widely used research tools to know the tentative trait of prenatal androgens, a diversity of physiological and psychological conditions, athletic ability and sexual orientation $[10,22,23]$. The differentiation of gonads, 
fingers, and toes is influenced by HOXA and HOXD genes. HOXA and HOXD genes are also necessary for finger length development and differentiation [24]. Congenital Adrenal Hyperplasia (CAH) is an anomalous hormonal environment that does not function correctly with the adrenal glands [25]. The 21-hydroxylase deficiency, results in the production of surplus quantities of masculine hormones by the adrenal glands [26]. However, researchers Okten and his colleagues studied digit ratio (2D:4D) and 21-hydroxylase deficiency in male (right palm) patients and reported lower digit ratio confirm the 21-hydroxylase deficiency than female and male controls. Women with CAH had a much lower second to fourth digit ratio than women without $\mathrm{CAH}$ on the right hand and on the left hand, men with $\mathrm{CAH}$ had a much lower digit ratio (2D:4D) than men without CAH [27]. Similarly, researchers [28] reveal the relationship between low digit ratio and $\mathrm{CAH}$. This characteristic also supports a combination of low digit ratio and elevated Fetal Testosterone concentrations [29].

\section{Relationship Between Digit Ratio (2d:4d) With Sports Performance}

Researchers [20] widely reviewed the most correlational studies and postulated that low second to fourth digit ratios (high prenatal testosterone and low estrogen hormone) could be a determinant of high sport performance. However, the high performance of rugby depends on low digit ratios [19]. The researchers also discovered differences in the low right-left digit ratios to be a determining factor in elite rugby performance. Keshavarz and his team (2017) studied on three male groups of Wrestlers; they are:

a) World class elite Greco-Roman wrestlers.

b) Collegiate non-elite wrestlers.

c) Sedentary age matched control.

The lower right- and left-hand digit ratios of world class wrestlers were predictors of high wrestling performance compared to other groups [30]. The achievement of the competition phase in team sports was also associated with the ratio of digits (2D:4D). The second to fourth digit ratio was therefore likely to have an impact on the possible athleticism [31]. Similarly, lower digit ratio (high prenatal androgens) has been shown to indicate the sport performance of soccer, surfing, sprinting, endurance, hand grip strength, rowing, kabaddi, swimming, Tennis [8,13-18,32].

\section{Digit Ratio as Soccer Performance Determinant}

High prenatal testosterone and low prenatal estrogen hormones are likely to be a strong predictor of soccer performance [7]. Competitive achievement is a major objective of soccer in connection with prenatal androgenization [31]. This prenatal situation influences the judgment of the visual perception [13]. Therefore, according to [7], "Striking a moving opponent or ball requires fine judgment of distance. Determining the exact point of impact demands an accurate perception of the surface of the target as it moves through space" (p.128). However, researchers studied on different types of soccer players and noticed 'professional', 'International' and ' 1 st team players' had lower digit ratio (2D:4D) than the 'control group', 'youth team' and the 'players who had not represent their country' respectively [13]. Similarly, the International presence of the player in a match is greater for the lower digit ratio individuals [7]. The lower digit ratio could therefore provide an additional discriminator to help estimate soccer capability. Prenatal testosterone exposure also influences professional soccer players' aggressive behavior. Researchers indicated that exposure to adult and prenatal testosterone detects the number of fouls per match that confirm the aggressiveness of players [33]testified by a low second-to-fourth digit ratio (2D:4D . Furthermore, aggression guarantees the dominant behavior that is essential in competitive sport.

\section{Association among Digit Ratio, Visual-Spatial Ability and Left Handedness}

Digit ratio is a putative indicator of sport performance differences [34]. A study concerning several sports related psychological variables (mental toughness, aggression, optimism scale, coping strategies, and goal orientations) with masculine digit ratio reported high scores of optimistic dispositions than those with feminine digit ratio. The study also claims that mental toughness partly determined on gestation period [34] that benefited for gender, age and sporting experience [35]. Mental rotation score test [36] can measure the visual-spatial intelligence [36-38]. Manning and Taylor found negative association between lower digit ratio and high mental rotation scores in males. So, the visual spatial intelligence may partially develop on intrauterine life [13]. High prenatal testosterone exposure is likely to associated with handedness $[39,40]$. Left-handed people dominated by the right hemisphere and assists visual spatial ability [41]. Interestingly, androgenisation exposure influence the right palm more than the left palm $[27,42,43]$. Right palm digit ratio is also significantly connected with several psychological and behavioral traits compared to the left palm digit ratio [43].

\section{Cognitive Abilities Influence on Soccer Performance}

Most team sports, particularly in soccer players, need to pursue numerous situations that are changing quickly [44]. Elite players perceive the situations and make the appropriate choice at the right moment $[45,46]$. Therefore, technical and tactical ability influence the outcome of the match $[47,48]$. Elite players perform the technical and tactical skills better in compared non-elite counterparts [49]. However, researchers postulated that distinguished correlations in male between more masculine digit ratio (lower digit ratio) and in visual-spatial ability $[13,22]$. On the other side, females have prone to more feminine digit ratios (higher second to fourth digit ratio) should relate to higher scores for depression (Repeat). Therefore, high prenatal testosterone exposure is likely to be predictor of soccer performance as well as cognitive ability [13]. Research also shows that human behavior and the status of cognition can result from prenatal androgenization [50].

\section{Conclusion}

Most correlational study reveals the negative relationships between lower digit ratio and sports performance. Low second to 
fourth digit ratio (2D:4D) can be an indicator in scouting potential athletes especially soccer players. In multifaceted aspects, lower digit ratio is likely to be a potential indicator of soccer specific skill performance. Further studies are required to clarify whether lower second to fourth digit ratio could predict the soccer skill performance in multifaceted aspects including passing, dribbling, control, shooting and decision making within a dynamic situation. In addition, we realized that sporting success might be depended on our hands' fingers length ratio along with other variables.

\section{Acknowledgment}

The researchers are thankful to Indian Council for Cultural Relations (ICCR), Ministry of External Affairs for their financial consideration.

\section{References}

1. McIntyre MH (2006) The use of digit ratios as markers for perinatal androgen action. Reproductive Biology and Endocrinology pp. 4-10.

2. Manning JT, Scutt D, Wilson J, Lewis Jones DI (1998). The ratio of 2nd to 4th digit length: A predictor of sperm numbers and concentrations of testosterone, luteinizing hormone and oestrogen. Human Reproduction (Oxford, England) 13(11): 3000-3004.

3. Manning J, Kilduff L, Cook C, Crewther B, Fink B (2014). Digit Ratio (2D:4D): A Biomarker for Prenatal Sex Steroids and Adult Sex Steroids in Challenge Situations. Frontiers in Endocrinology p. 5.

4. Garn SM, Burdi AR, Babler WJ, Stinson S (1975) Early prenatal attainment of adult metacarpal-phalangeal rankings and proportions. American Journal of Physical Anthropology 43(3): 327-332.

5. George F W, Griffin JE, Leshin M, Wilson JD (1981) ENDOCRINE CONTROL OF SEXUAL DIFFERENTIATION IN THE HUMAN. Fetal Endocrinology 341-357.

6. Coates JM, Gurnell M, Rustichini A (2009) Second-to-fourth digit ratio predicts success among high-frequency financial traders. Proceedings of the National Academy of Sciences 106(2): 623-628.

7. Manning John T (2002) Digit Ratio (A pointer to Fertility, Behavior, and Health). United States of America: Rutgers University Press.

8. Manning John T, Churchill AJG, Peters M (2007) The effects of sex, ethnicity, and sexual orientation on self-measured digit ratio (2D:4D). Archives of Sexual Behavior 36(2): 223-233.

9. Kratochvíl L, Flegr J (2009) Differences in the $2^{\text {nd }}$ to $4^{\text {th }}$ digit length ratio in humans reflect shifts along the common allometric line. Biology Letters 5(5): 643-646.

10. Manning JT, Bundred PE (2000) The ratio of 2nd to 4th digit length: A new predictor of disease predisposition? Medical Hypotheses 54(5): 855-857.

11. Malik A, Singh B (2014) DIGITAL FINGER RATIO (2D:4D) AND SALIVARY TESTOSTERONE LEVEL IN ELITE SPORTSMEN AND NON-SPORTSMEN.

12. Liu J, Portnoy J, Raine A (2012) Association between a marker for prenatal testosterone exposure and externalizing behavior problems in children. Development and Psychopathology 24(3): 771-782.

13. Manning JT, Taylor RP (2001) Second to fourth digit ratio and male ability in sport: Implications for sexual selection in humans. Evolution and Human Behavior: Official Journal of the Human Behavior and Evolution Society 22(1): 61-69.

14. Manning JT, Hill MR (2009) Digit ratio (2D:4D) and sprinting speed in boys. American Journal of Human Biology: The Official Journal of the
Human Biology Council 21(2): 210-213.

15. Hone LSE, McCullough ME (2012) 2D:4D ratios predict hand grip strength (but not hand grip endurance) in men (but not in women). Evolution and Human Behavior 33(6): 780-789.

16. Longman D, Stock JT, Wells JCK (2011) Digit ratio (2D:4D) and rowing ergometer performance in males and females. American Journal of Physical Anthropology 144(3): 337-341.

17. Sudhakar, Honnamachanahalli H, Majumdar P, Umesh V, Panda K (2014) Second to Fourth Digit Ratio Is a Predictor of Sporting Ability in Elite Indian Male Kabaddi Players. Asian Journal of Sports Medicine 5(3).

18. Sudhakar HH, Veena UB, Tejaswi RN (2013) Digit ratio (2D:4D) and performance in Indian swimmers. Indian J Physiol Pharmacol 57(1): 7276.

19. Bennett M, Manning JT, Cook CJ, Kilduff LP (2010) Digit ratio (2D:4D) and performance in elite rugby players. Journal of Sports Sciences 28(13): 1415-1421.

20. Kim TB (2016) Why is digit ratio correlated to sports performance? Journal of Exercise Rehabilitation 12(6): 515-519.

21. Mazur A, Booth A (1998) Testosterone and dominance in men. Behav Brain Sci 21(3): 353-363; discussion 363-397.

22. Bailey AA, Hurd PL (2005) Depression in men is associated with more feminine finger length ratios. Personality and Individual Differences 39(4): 829-836.

23. Zheng Z, Cohn M (2011) Development basis of sexually dimorphic digit ratios. Proceedings of the National Academy of Sciences of the United States of America 108(39): 1628-16294.

24. Manning JT, Callow M, Bundred PE (2003) Finger and toe ratios in humans and mice: Implications for the aetiology of diseases influenced by HOX genes. Medical Hypotheses 60(3): 340-343.

25. New M, Yau M, Lekarev O, Lin Su K, Parsa A et al. (2000) Congenital Adrenal Hyperplasia. In K. R. Feingold, B. Anawalt, A. Boyce, G. Chrousos, K. Dungan, A. Grossman, D. P. Wilson (Eds.), Endotext. Retrieved from

26. Okten A, Kalyoncu M, Yariş N (2002) The ratio of second- and fourthdigit lengths and congenital adrenal hyperplasia due to 21-hydroxylase deficiency. Early Hum Dev 70(1-2): 47-54.

27. Brown WM, Hines M, Fane BA, Breedlove SM (2002) Masculinized finger length patterns in human males and females with congenital adrenal hyperplasia. Horm Behav 42(4): 380-386.

28. Hönekopp J, Watson S (2010) Meta-analysis of digit ratio 2D:4D shows greater sex difference in the right hand. American Journal of Human Biology: The Official Journal of the Human Biology Council 22(5): 619630.

29. Lutchmaya S, Baron Cohen S, Raggatt P, Knickmeyer R, Manning JT (2004). 2nd to 4th digit ratios, fetal testosterone and estradiol. Early Human Development 77(1-2): 23-28.

30. Keshavarz M, Bayati M, Farzad B, Dakhili A, Agh Alinejad H (2017) The Second to Fourth Digit Ratio in Elite and Non-Elite Greco-Roman Wrestlers. Journal of Human Kinetics 60(1): 145-151.

31. Moffit DM, Swanik CB (2011) The association between athleticism, prenatal testosterone, and finger length. Journal of Strength and Conditioning Research 25(4): 1085-1088.

32. Hsu CC, Su B, Kan NW, Lai SL, Fong TH et al. (2015) Elite collegiate tennis athletes have lower 2D: 4D ratios than those of nonathlete controls. Journal of Strength and Conditioning Research 29(3): 822-825.

33. Perciavalle V, Di Corrado D, Petralia MC, Gurrisi L, Massimino S, Coco M (2013) The second-to-fourth digit ratio correlates with aggressive behavior in professional soccer players. Molecular Medicine Reports $7(6): 1733-1738$. 
34. Golby J, Meggs J (2011) Exploring the Organizational Effect of Prenatal Testosterone Upon the Sporting Brain. Journal of Sports Science \& Medicine 10(3): 445-451.

35. Nicholls AR, Polman RCJ, Levy AR, Backhouse SH (2009) Mental toughness in sport: Achievement level, gender, age, experience, and sport type differences. Personality and Individual Differences 47(1): 73 75.

36. Vandenberg SG, Kuse AR (1978) Mental rotations, a group test of threedimensional spatial visualization. Perceptual and Motor Skills 47(2): 599-604.

37. Guillot A, Champely S, Batier C, Thiriet P, Collet C (2007) Relationship Between Spatial Abilities, Mental Rotation and Functional Anatomy Learning. Advances in Health Sciences Education 12(4): 491-507.

38. Neubauer AC, Bergner S, Schatz M (2010) Two- vs. three-dimensional presentation of mental rotation tasks: Sex differences and effects of training on performance and brain activation. Intelligence 38(5): 529539.

39. Lust JM, Geuze RH, Van de Beek C, Cohen Kettenis PT, Bouma A et al. (2011) Differential effects of prenatal testosterone on lateralization of handedness and language. Neuropsychology 25(5): 581-589.

40. Coren S (1998) Prenatal testosterone exposure, left-handedness, and high school delinquency. Behavioral and Brain Sciences - BEHAV BRAIN SCI 21(3): 369-370.

41. Geschwind N, Galaburda AM (1985) Cerebral lateralization. Biological mechanisms, associations, and pathology: I. A hypothesis and a program for research. Arch Neurol 42(5): 428-459.
42. McFadden D, Shubel E (2002) Relative lengths of fingers and toes in human males and females. Horm Behav 42(4): 492-500.

43. Williams TJ, Pepitone ME, Christensen SE, Cooke BM, Huberman AD (2000) Finger-length ratios and sexual orientation. Nature 404(6777): 455-456.

44. Schumacher N, Schmidt M, Wellmann K, Braumann KM (2018) General perceptual-cognitive abilities: Age and position in soccer. PLoS ONE 13(8).

45. Gréhaigne JF, Godbout P, Bouthier D (2001) The Teaching and Learning of Decision Making in Team Sports. Quest 53(1): 59-76.

46. Baker J, Côté J, Abernethy B (2003) Learning from the experts: Practice activities of expert decision makers in sport. Research Quarterly for Exercise and Sport 74(3): 342-347.

47. Rampinini E, Impellizzeri FM, Castagna C, Coutts AJ, Wisløff U (2009) Technical performance during soccer matches of the Italian Serie A league: Effect of fatigue and competitive level. Journal of Science and Medicine in Sport 12(1): 227-233.

48. Ben Ounis O, BenAbderrahman A, Chamari K, Ajmol A, BenBrahim M (2013) Association of Short-Passing Ability with Athletic Performances in Youth Soccer Players. Asian J Sports Med 4(1): 41-48.

49. Ali A, Williams C, Hulse M, Strudwick A, Reddin J, Howarth L, McGregor S (2007) Reliability and validity of two tests of soccer skill. Journal of Sports Sciences 25(13): 1461-1470.

50. Hönekopp J, Bartholdt L, Beier L, Liebert A (2007) Second to fourth digit length ratio (2D:4D) and adult sex hormone levels: new data and a metaanalytic review. Psychoneuro endocrinology 32(4): 313-321.
This work is licensed under Creative Commons Attribution 4.0 License

To Submit Your Article Click Here: Submit Article

DOI: $10.32474 /$ OSMOAJ.2019.03.000154

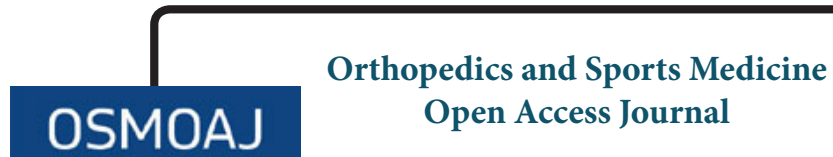

\section{Assets of Publishing with us}

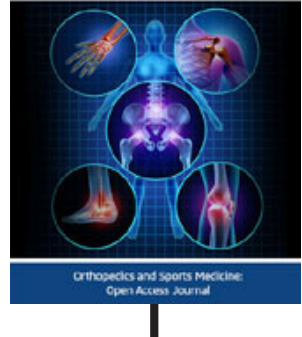

- Global archiving of articles

- Immediate, unrestricted online access

- Rigorous Peer Review Process

- Authors Retain Copyrights

- Unique DOI for all articles 